\title{
Sudanese young people building capital in rural Australia: the role of mothers and community
}

\author{
Ninetta Santoro \\ University of Strathclyde, Scotland, United Kingdom \\ Jane Wilkinson \\ Monash University, Victoria, Australia
}

\begin{abstract}
This article draws on an ethnographic study that consisted of in-depth case studies of eight Sudanese young people of refugee background living in rural Australia. Prompted by concern over deficit views of young refugees that pervade educational literature, we aimed to understand what facilitates their successful resettlement into Australian rural communities. We were particularly interested in understanding the strengths, resources and capital they draw upon and generate through their participation in out-of-school social and learning contexts, as well as within family and community networks. Here, we focus on one of the study's participants, Samir. We highlight how his mother was instrumental in providing a safe and secure home environment where significant bonding capital was generated, as well as how she facilitated her son's participation in community and ethnic networks, thus enabling him to acquire bridging and linking social capital. We conclude by discussing the implications for schools and for research.
\end{abstract}

Keywords: ethnography, refugee integration, social capital, rural Australia, refugee education

\section{Introduction}

They will say I'm confident, powerful, funny and active. Yeah!

The comment above is from one of our interviewees in response to a question asking him how he might be described by someone who knows him. Samir is thirteen years old, from Sudan, of refugee ${ }^{i i}$ background and the second eldest in a family of seven boys and one girl. He is confident, academically capable, socially adept, assertive, caring, outgoing and positive. He, and seven other young people of Sudanese refugee background aged between thirteen and seventeen, were research participants in an ethnographic study that investigated how out-of-school activities, family and community networks contributed to them accruing confidence, self esteem and successfully settling into an Australian rural community.

Research into the education of refugee students is well established. A significant body of literature has identified and documented the challenges facing refugee students and their teachers. For example, McBrien's review of literature in the USA suggested that refugee students, as a group, are the most 'vulnerable to school failure' (McBrien 
2005, 332). Other, more recent literature, suggests that refugee children have educational needs that are different from other immigrant or culturally diverse students (Bačáková, 2011; Taylor and Sidhu, 2012; Pugh, et al., 2012). Refugee children are likely to have histories of extreme trauma and violence as well as having experienced lengthy periods of displacement. They 'are positioned as especially problematic because of fears about the values they might import from dysfunctional home countries' (McPherson 2010, 547), as well as concerns about the impact of fractured family relationships and experiences of violence and deprivation in refugee camps. Additionally, often they have little, or no experience of formal schooling and have little or no formal literacy in their first language (Oliver et al., 2009; Strekalova and Hoot, 2008; Woods, 2009).

There is evidence that some Australian schools find it difficult to address the needs of refugee students (eg. Windle and Miller, 2013; Matthews, 2008). This is particularly the case for schools in regional or rural ${ }^{\mathrm{iii}}$ locations where there has been an increase in refugee students in recent years (Major, Wilkinson, Langat and Santoro, 2013). The Australian government, in response to declining populations, labour market shortages in regional and rural areas and increasing demands on services in urban areas of high immigration (Institute for Community Ethnicity and Policy Initiatives, 2005), has encouraged increased immigrant resettlement outside large urban centres. In the mid 2000s, Sudanese refugees represented one of the fastest growing groups in Australia, with 19,050 Sudan-born people in Australia - an increase of $287.7 \%$ from the 2001 census, and until recently, they represented the majority of refugees settled in regional and rural areas (Department of Immigration and Citizenship, ND). However, because Australian regional and rural schools have generally had culturally homogenous student populations, teachers often lack the expertise to engage productively with ethnically diverse students. This is often compounded by lack of access to resources, appropriate policies and broader public infrastructure (Edgeworth, 2012; Wilkinson and Langat, 2012).

The overall impression one gains from the research into refugee resettlement and education is that African refugees are needy and dependent rather than self-determining and independent. They are often understood and characterised in terms of what they lack. Prompted by concern over deficit views of young African refugees that pervade educational literature, we were keen to move beyond schools to understand the strengths, resources and social capital young people of African refugee background draw upon and generate through their participation in a range of out-of-school activities, including family and community networks. It is well accepted that strong family and community networks and participation in out-of-school activities can contribute to increased confidence, self esteem and positive social relationships (Eccles et al., 2003; Bohnert, et al., 2013). Thus, the study on which this paper reports, investigated how out-of-school activities and family and community networks facilitated the generation of social capital and the successful resettlement into Australian rural communities of eight young people of Sudanese refugee background. In this article we focus on one case study participant, Samir, whose mother was instrumental in providing a safe and secure home environment where significant bonding capital was generated. She also facilitated her son's participation in community and ethnic networks, thus enabling him to acquire bridging and linking social capital.

\section{The study}


An ethnographic approach was chosen for this study because it is well suited to understanding the perspectives of those located within a particular social world and involves the collection of rich descriptive data gathered over a sustained period from a range of participants, and in context. We wanted to come to know our participants 'in action' at home, with friends, and with members of their community. Ethnographic data collection techniques such as observations, casual conversations, photographs, fieldnotes and interviews promised to generate rich and complex data. The study consisted of in-depth case studies of eight Sudanese young people, four males and four females aged between 13 and 17, in rural Australia. The young people were located in two separate towns of about 40,000 people and 60,000 people, and approximately 200 kilometres and 450 kilometres from Sydney, respectively. The towns have small but growing populations of Sudanese families, some of whom have been in Australia for 10 years. A snowball sampling technique was used whereby we recruited through word of mouth within the Sudanese community and immigrant support agencies. Young people who were identified by community elders and professionals who work within the communities, as having successfully settled, were invited to be part of the research. 'Successfully settled' was defined broadly, and included, engagement with the wider community and social networks, the demonstration of responsibility/civic mindedness, and positive attitudes to school. The key research questions were: What types of social capital do young people of Sudanese refugee background generate via their participation in out-of-school activities and family and community networks? How does the acquisition of social capital contribute to the successful resettlement of young people of Sudanese refugee background?

The main data collection methods used in the study were observations, fieldnotes and semi-structured interviews. Observations occurred over a nine month period during a range of out-of-school activities, such as sports practices and matches, youth group activities, as well as home visits. The home visits occurred on a fortnightly basis with the researchers 'catching up' with the family for about one hour at a time. During these visits, we observed how the young people and their family members interacted, we caught up on recent events and news, chatted with the young people, their parents and siblings. Often there were other visitors present, including relatives, neighbours, family friends members of the Sudanese community and service providers. Observations of each young person participating in formal out-of-school activities occurred at least three times for up to 3 hours at a time over a six month period. We observed the nature of their interactions with other young people and other adults at the out-of-school activity such as coaches, activity organisers and parents of other participants. On occasions, we picked up the young people from their home and drove them to the activities. This enabled us to engage in informal and unplanned conversations with them. We kept detailed field-notes about our observations, planned discussions, 'chance' conversations and remarks. 
Data were also collected through semi-structured interviews with each of the young people twice over a period of about six months. The interviews lasted approximately one hour. The researchers used as a stimulus for the interviews, photographs the young people took using digital cameras that had been given to them at the beginning of the study. They were each asked to take photos of people, places and things that were important to them and that they associated with feeling successful and feeling good about themselves. The interviews usually began with the young person showing the researchers their photographs and talking about why they were important. Interviews were also conducted with parents or caregivers as well as an adult person nominated by the young person as someone who was important in their lives and contributed to them feeling good about themselves; for example, a sports coach, leader of a community group the young person belonged to, family friend or mentor. These interviews were intended to pick up on researcher observations and allow further exploration, as well as elicit various perspectives from the interviewee about the young person and his/her outof-school resources and activities. In some cases, interpreters were used during the interview if the interviewee's English language competence was limited. Interviews were audio recorded and transcribed verbatim.

In this article we report on only one of the case study participants, Samir. We draw on our field-notes of our observations of him at home, at football practice sessions and matches, as well as field-notes of our informal interactions and conversations with a range of people we met at his home and at football. We also draw on data from two semi-structured interviews with Samir, an interview with his mother, an interview with Jenny (a volunteer mentor) and with Sue (a migrant support worker).

All of Samir's siblings live in Australia, except for his sister who still lives in Sudan. The family comes from a relatively large city in Southern Sudan where Samir's parents ran a small business. They are Muslim and speak Sudanese Arabic at home. The family has been in Australia for four years, three of which were spent in Sydney. Prior to coming to Australia the family was in a refugee camp in Egypt for two years. They moved to Riverbank a year ago because they knew other Sudanese people who had moved there and recommended it. Riverbank is a town of about 40,000 people and 200 kilometres from the nearest major city. It has a growing population of Sudanese families and a variety of community support services for immigrants and refugees. The children's father, who is still in Sudan, has been separated from the family for many years. He has recently been located by an international humanitarian organisation and is waiting to come to Australia. A daughter was also separated from the family in Sudan and efforts are being made to try and locate her.

When data collection began, Samir was in his first year of secondary school. Field-notes about conversations with Samir during researcher visits to the family home, as well as interviews with him, reveal that he likes living in Riverside, enjoys school, likes his teachers and has many friends, both Sudanese and non-Sudanese. He reports doing well academically, has won a number of achievement awards as well as having received good school reports which he happily showed us. He participates in sports activities and has a positive attitude towards learning. He is involved in a number of outof-school activities including Youth Groups and Holiday Programmes run by the Riverside council. He nominated football as the most important of his out-of-school activities, and it was this activity we chose to observe.

Aisha is Samir's mother. She is 33, had some formal education in Sudan (approximately lower secondary level) and went to English classes when she first 
arrived in Australia. She is currently a fulltime homemaker but hopes to find part time cleaning work in Riverside.

Jenny is a volunteer who has been helping refugees in the Riverbank community and assisting them with their applications for Australian citizenship as well as helping them study the road rules for their driving tests. She has become a close friend of the family, and spends a lot of time visiting them and accompanying them on social outings. Samir nominated Jenny as an important person in his life because she helps his mother and his family. Her importance to the family was raised a number of times during our informal conversations with Samir and Aisha.

Sue is a migrant support worker at the migrant resource centre in town. She is responsible for linking migrants and refugees in Riverside to support services such as counselling, housing, health, education, translation services and so on. She was nominated by Samir as an important person in his life because, like Jenny, she helps his mother and was responsible for introducing him to the holiday and youth programs in Riverside.

As is often the case when ethnographic methods are employed, data analysis and data collection were simultaneous processes. As soon as the research site was entered and decisions made about what or whom to observe, in effect, analysis began. Similarly, the process of engaging in conversations and semi-structured interviews with participants meant that data were generated through a two-way interactive process. Early data collection and the associated analysis shaped what further data were collected. After the data collection was complete, our approach to the analysis of the observations, field-notes and interview data was informed by Situational Analysis (Clarke, 2005). It is what Khaw calls 'an analytic diagramming tool' $(2012,138)$ because it involves the production, through drawing, of a series of maps that make the 'invisible and inchoate social features of the situation more visible' (Clarke 2005, 572). Situational analysis involves the production of three types of maps: situational maps (both 'messy' and 'relational'), 'social worlds/arenas maps' and 'positional maps'. These facilitate the identification of the most salient human and non-human elements in the situation under investigation. It became clear to us after several readings of the data that the salient human elements facilitating Samir's successful resettlement were his mother, his siblings and friends, members of the Sudanese community in Riverside, social workers, his football coach. The salient non-human elements were: the geography and physical nature of the town in which his family lived; the welfare and social support systems, including youth clubs, sporting clubs. In this article, we give particular attention to the human elements, with a focus on Samir, his mother, Aisha and other members of the family's social network.

\section{The concept of capital}

Many scholars have used the concept of capital in a variety of ways to understand and explain how human action is related to acquiring and securing some form of capital or combination of capitals, including economic capital, cultural capital and social capital (eg. Bourdieu, 1987; Coleman, 1988, Bassani, 2008). The concept of social capital, in particular, has developed importance as a theoretical and analytical lens across a broad range of fields. It is

a form of power, a currency, a resource: it can be utilised, traded, exchanged, drawn upon, invested or cashed in. Social capital is a form of energy, a force; it is a capacity, a 
facility that can be deployed and activated towards some desired goal (McGonigal et al. 2007, 80).

Social capital comprises the 'assets' and 'resources' derived from the relationships that occur between people and groups of people. According to Putnam, social capital is generated by the 'connections among individuals - social networks and the norms of reciprocity and trustworthiness that arise from them' (Putnam, 2000: 19). Putnam extended his concept of social capital to include bonding and bridging capital (2000) which are the kinds of social capitals generated by individuals' participation in different kinds of social networks. Bonding capital is 'a social "glue" that sticks like people together' (Brough et al. 2006, 407) and creates tight but inward looking networks. Family networks and ethnic communities can be key sources of bonding capital. It is 'gained from participation in local social networks that are most often homogenous and supportive, and provide a sense of belonging' (Santoro, 2013, 962). According to Terrion,

Bonding social capital provides a sense of belonging and is critical to the sense of well-being of the members of families and groups and fulfils immediate needs for belonging, love, emotional support, and solidarity $(2006,157)$.

Bridging social capital is obtained from participation in heterogeneous, outward-looking and more loosely tied social networks that generate 'broader identities and reciprocity' (Putnam, 2000, 20). It enables the crossing of social groups and acts as 'a social lubricant [...] for allowing different kinds of people to mix together freely' (Brough, et al. 2006, 407). The kinds of relationships and networks that build bridging capital are usually established and maintained outside the home and beyond familiar and local communities. A third type of capital, linking capital, is generated via relationships with 'sympathetic individuals in power ... in order to leverage resources, ideas, and information from formal institutions beyond the community' (Woolcock in Terrion 2006, 158).

Some scholars argue that bridging capital and linking capital are more valuable than bonding capital (Woolcock and Narayan in Brough et al., 2006) and are accessed and built via more powerful and diverse networks. These capitals are thought of metaphorically, as either horizontal or vertical. In the case of bridging capital, networks extend outwards, horizontally. In the case of linking capital, networks extend upwards, vertically (Woolcock in Terrion, 2006). Bonded networks on the other hand, are circuitous in nature. Regardless of the strength of bonding relationships, it is unlikely that bonding capital alone will facilitate access to the resources that are necessary for the successful integration into a new community. However, the acquisition of bonding capital is a precursor to the acquisition of bridging capital and linking capital - it can enable and facilitate individuals moving from family and close social networks into the community more broadly. Therefore, there is a strong and positive relationship between these forms of capital.

Putnam's concept of social capital has come under criticism for a number of reasons, including the difficulty in measuring it, and its focus on only the positive elements of relationships. Its proponents are often accused of paying scant attention to the negative elements of social relationships such as the associated obligations and restrictions, as well as the development of behaviours and attitudes in group members that are anti-social (Tzanakis 2013). Nonetheless, Putnams work on social capital concept has been particularly useful to us because social connectedness, in its various 
forms, can be closely linked to feelings of wellbeing for refugees and therefore, contribute to successful resettlement (Murray, 2010).

\section{The generation of bonding capital}

It is clear to us that bonding capital is generated within Samir's family relationships. Our observational field-notes suggest he is happy and feels secure and valued. He is proud of his family and was keen to introduce each of his brothers to us when we first visited, especially his new-born baby brother, to whom he was demonstrably affectionate. He also appeared very close to Aisha, showing love and concern for her. He knows his mother values him and believes in his ability to do well at school. He said she tells him often that he is 'a good boy', 'a clever boy', and that she loves him. Aisha said she is confident Samir will succeed in realising his ambition to become a doctor. During our visits to their home, Samir willingly helped his mother with domestic chores, and on one occasion, Aisha proudly offered us biscuits Samir had made. She told us several times that she appreciates his help with housework and the responsibility he takes for his younger brothers' care.

Aisha is largely responsible for making possible the generation of bonding capital between members of the family. As is the case for many refugees (Strang and Ager, 2010), Samir's family was separated for many years - developing bonded relationships are likely to be of paramount importance. It is not uncommon for refugee women, many of whom are sole parents, to become the head of their family in the absence of their husband (Lenette et al., 2012), and to carry responsibility for ensuring the emotional, social and physical wellbeing of the family. It might be argued that Aisha's investment in her family's wellbeing is no different from that of mothers in general. However, because of the trauma she has experienced and the fractured nature of her past family life, providing emotional stability and security may require her to draw on significant reserves of emotional resilience.

Both Jenny and Sue spoke of how they see Aisha as pivotal to the family's happiness and wellbeing. According to Sue, 'there's a strong family connection' that is reflected in the care that each family member shows for the other. Jenny said of Aisha:

She's such an amazing woman because she has just got this happiness about her and her home is really happy and loving and she's got .... you know, her boys are very lucky because yeah, she's got like a great sense of humour and she's warm and she's loving.

She is such as strong leader of her family and for those children ... To see and the amount of resourcefulness and resilience of this woman is amazing. I think it's an absolute credit to her really, yeah (Sue).

... it's that word resilience, she's just got it in spades (Jenny).

Resilience is an 'individual's psychological ability to overcome, learn from and adapt positively to life's adverse events' (Lenette et al. 2012, 2). Jenny and Sue attributed Aisha's resilience in part, to the strong social networks within the Sudanese community in Riverside whereby members take up the role of an extended family and facilitate the generation of bonding capital. Now that Samir's family is settled in Riverside, Aisha has become a leader within the Sudanese community and is key to maintaining and developing the family's connection to other Sudanese families. She is well known and 
the family is socially active. Frequently, there are dinners and parties, either hosted by, or attended by the family. Samir talked fondly of these events where there is food, dancing and singing. He told us he feels a strong sense of belonging to the Sudanese community and is proud to be Sudanese. Aisha is also held in high regard by other Sudanese women in Riverside. When we visited the family home there were usually other women present, some of whom had come for counsel. On one visit, Aisha was absent because she was assisting a newly arrived Sudanese family settle into their new home.

One of the first photographs Samir took was of a Sudanese woman he called his aunty (not a relative but a close friend of his mother). He said during our interview that she was an important person in his life because 'she's like, she's kind of like my mum. She looks after me and my brothers if my mum is away'. His aunty also takes an interest in what he is doing at school and encourages him to do well. She is what Collins refers to as an 'other mother' (Collins in McCray et al., 2002), that is, a key female figure who is mother-like in the demonstration of care-work.

Samir: She [his aunty] is like really interested in my schoolwork and stuff. And when we had the baby party [a celebration for the birth of the new baby] I had to catch up on all my homework, yeah, and she's really interested in my schoolwork.

Interviewer: How do you feel when people ask you about how school's going and about ask about your school work? How does that make you feel?

Samir: It makes me feel good. It makes me feel like they're interested in me.

Research suggests that strong bonding capital, especially during resettlement periods provides support, confidence and self-esteem and assists refugees manage the difficulties they face in resettling and adjusting to an unfamiliar environment (McDonald et al., 2008; Strang and Ager, 2010). Acquiring bonding capital through close family and community networks may enable individuals to develop the confidence to extend their networks beyond those that are familiar to them, and may, ultimately, enable them to acquire bridging capital.

We believe that underpinning the production of bonding capital, both within Samir's family and the Sudanese community is Aisha's generation of emotional capital, a concept first developed by Helga Nowotny in relation to the resources generated by women through familial relationships and care (1981). It has since been used by scholars working across a wide range of areas in order to describe parents', and particularly mothers', emotional investment in their children's well-being (e.g., Reay, 2000; Santoro, 2010; Hutchison, 2012; Nixon, 2011). Mothers, who are most frequently the primary caregiver in families, often engage in significant emotional labour. Aisha's emotional labour contributed to a stable and secure family life that facilitated successful relationships between family members and members of the Sudanese community. Thus, in turn, these relationships made possible the generation of bonding and bridging capital.

\section{The generation of bridging capital and linking capital}


Even though Aisha's own bridging capital was limited, she was instrumental in enabling Samir to access networks beyond those of the immediate family and the Sudanese community. Thus, he was able to build bridging capital. For example, a major reason for obtaining her driving licence was to drive Samir to football training and the youth club in the evenings and on the weekends. She went to English classes to improve her English in order to obtain paid employment and better provide for her family. In similar ways, the refugee women in McPherson's research regarded themselves as 'intrinsically connected to community' $(2010,561)$ and saw their education as 'facilitating out-comes for themselves, for their families, [and] for their communities (562).

Strang and Ager (2010) emphasise the need for refugees to develop 'social bridges' in order to avoid separatism and isolation. Friends can act as important social bridges. Samir's friendships groups were heterogeneous and included Sudanese boys as well as those from the wider Australian community. Aisha fostered his friendships with a wide circle of friends, and especially non-Sudanese boys, by encouraging him to bring them home and allowing them to stay overnight sometimes, a social practice that didn't occur in Sudan. His friends have taught him how to play football, computer games and in general, inculcated him into social activities that hold status for teenagers. His participation in these activities led to acceptance by his peers, and in turn, these friendships have led to further friendship networks. The football club was an important site that facilitated access to new social networks. It was through football that Samir became friends with a wide range of non-Sudanese boys who lived outside his immediate neighbourhood. He seemed to us to be well liked by the other boys; they appeared to function well as a team on the field and we observed them enjoying jokes together off field. Our casual conversation with the football coach suggested that he 'kept an eye' on Samir to ensure he was 'doing ok'. During observed matches, the other boys' parents seemed to know Samir and cheered him on and encouraged him as much as they did their own sons. Because Aisha understood the value of his involvement in football, she prioritised the purchase of football equipment for him and the cost of the weekend trips away with the team.

Like most parents, Aisha is keen for her children to succeed at school. However, she is unfamiliar with Australian systems of schooling, finds Samir's school intimidating at times and cannot help him with homework or serve on parent committees because of her limited English. However, like some of the Somalian refugees in Ramsden's and Taket's, study she demonstrated significant personal agency and resilience in the face of these challenges. She regularly attended parent teacher evenings at Samir's school because she understands that this is an expectation in Australia. She believes her attendance indicates to the teachers, and to Samir, that she values education, is interested in his education and will do whatever she can to assist him succeed.

While Jenny and Sue play a part in the bonded and bridging relationships of the family, they are also part of linking networks in that they made possible, connections with other organisations and the wider community and resources. It was through Sue that Samir was initially linked into the holiday program, the sports teams and the youth groups in which he participated. Sue said:

I just heard they [the family] were in Riverside and we had the Merge programme [a youth group] about to start [...] I we knew that if we could sign this lad on, it might be a really nice way for him to connect into the community. 
Sue also brought Jenny and Aisha together in a mentoring relationship where Jenny assisted Aisha study for the Australian citizenship test and her driving licence test, thus helping her and her family connect to the wider community.

Aisha was described by Jenny as being 'very good at finding help' and proactive in locating organisations and agencies that could provide her and her family with medical, education and social support. The Sudanese community also facilitated the generation of linking capital for the family. They moved to Riverside because they knew other Sudanese families who lived there and who not only recommended the town, but helped them get established and assisted them secure housing, choose appropriate schools and connect to local service agencies. In their report into the resettlement of African refugees in Australia, The Community Relations Commission (2006) claims;

despite the seemingly overwhelming challenges faced by African humanitarian entrants during settlement, African communities have displayed great strength, commitment, and resourcefulness in addressing community needs and assisting new arrivals with the settlement process (132).

\section{Discussion}

Resilience and strength might be seen to drive Aisha's strategy, commitment and determination to find out about, and access the support services her family requires, to establish a secure and supportive home, to connect with her children's schools and to maintain Sudanese cultural values and community networks. She does so despite having limited English language competence, despite carrying the responsibility of single parenthood, despite having little knowledge of formal education systems and despite the stress associated with resettlement in a new community. Her resilience and strength have been crucial in creating and facilitating opportunities for Samir to develop bridging and linking relationships within the Sudanese community and the wider Australian community in Riverside. The view of refugee women as resilient and strong positions them positively and as agentic, rather than as vulnerable and needy. However, Lenette et al. $(2012,2)$ caution against the 'dominating tendency to conceptualize resilience narrowly as an 'inner' capacity [because it] ignores or problematically reconfigures the 'outer' social worlds in which lives are embedded'. We do not want to suggest that resilience is an innate quality and a 'natural' quality - to do so would be to position other refugee women who do not demonstrate Aisha's resilience, as 'naturally un-resilient' and by implication, destined to struggle with the challenge of resettling their family. It is much more productive to look towards 'the processes of resilience rather than the traits of resilience' (Lenette et al. 2012, 3). In considering the processes that make resilience possible, it is important to consider the support Aisha received from agencies and organisations in Riverside and from people like Jenny and Sue who have been crucial to her development of confidence, strength and emotional wellbeing.

We do not want to suggest that country towns do not present any challenges to the effective resettlement of immigrants and refugees. They are often culturally homogenous and lack the support services available in cities where there are concentrated groups of immigrants from particular ethnic groups. However, the size of a rural town can also benefit refugee families. For example, the compactness of Riverside facilitated easier access to social hubs and participation in social activities, thus enabling bridging networks and connections to be established more easily. Samir's participation in football was made easier because of the shorter distances to travel to 
sports grounds. Furthermore, the small size of Riverside meant that Aisha was relatively relaxed about the safety of her children and the ways in which they were being integrated into the community. Compared to Sydney where she constantly worried about her children getting caught up with the wrong people and getting into trouble like other Sudanese young people she knew, Riverside was quieter, safer and had fewer negative influences and distractions for her children. In Riverside Aisha had greater control over her children and their activities, and knew where they were and what they were doing. The outcome for Samir was greater freedom to visit friends and socialise in community spaces such as shopping malls and parks because the environment was perceived by his mother to be safe, thus facilitating bridging relationships.

Some research suggests that as their children became increasingly integrated into the Australian community, refugee mothers can feel disenfranchised from their resettlement communities. For example, the refugee mothers in a study by Hebbani et al. (2009) connected their children's integration in Australia with the development of attitudes and the engagement with activities and social groups that led to a rejection of Sudanese values in favour of what they considered to be Australian values. These were the antithesis of what the mothers valued and wanted for their children. They felt that the parental authority they had in Sudan was being eroded in Australia and that they were powerless to discipline their children and influence their behaviour. Hebbani et al. claim when the mother rejects the

'Australianization' strategy adopted by their assimilating children, they (mothers) find it difficult to distinguish between feelings of rejection towards the Australian culture, and feelings of frustration and disconnection from their children (2009, 78).

Aisha's children's integration into Australian society did not signal for her a loss, or symbolic separation. She was able to adapt, and adjust her parenting practices and expectations because she felt connected positively to their lives beyond the home. This may have been due, in part, to living in a rural town where she knew where her children were, what they were doing and she knew the people who were with her children.

\section{Concluding remarks}

This research has found that Samir's participation in social, family and community networks contributed to the generation of various forms of social capital that were important to his successful resettlement in Riverside. It has also highlighted the important role his mother played in providing a secure and safe family life and facilitating his participation in ethnic and community networks beyond home. While we do not want to generalise from this single case to all refugee families and students, we believe our findings may resonate with researchers and teachers working in similar contexts. In particular, there are a number of implications for schools and for educational research. First, schools should be, and could be affective brokers of bridging and linking relationships for refugee students by valuing and building on students' existing out-of-school networks, recognising the potential of these networks for relationship building and the generation of social capital, as well as for the learning that can occur in out-of-school contexts and networks. Far too often students' out-ofschool lives and the networks to which they belong are not recognised for their relevance to refugee students' educational resettlement. Second, schools can learn a 
great deal from community organisations such as those to which Jenny and Sue belong. These organisations can be integral to successful refugee resettlement - their members may be able to offer insights into the experiences of refugee families that are not otherwise available. A challenge for schools is how to work productively with, and alongside a range of organisations, communities and individuals in order to facilitate the students' acquisition of social capital. Third, it is also important that schools recognise the resilience and resourcefulness that refugee students and their families can possess. The building of security, hope and optimism within families affected by trauma and dislocation, takes resourcefulness, strategy and strength on the part of parents and family members. For this reason, refugee parents and family members are potential resources to be drawn upon - their involvement in their children's schooling is essential. Schools need to find ways to encourage, foster and value their participation and engagement.

To conclude, we began this article by expressing our concerns over the deficit views of refugee young people that dominate much educational research. We believe there is a need for educational research into young people of refugee background that shifts the gaze from a 'discourse of despair' (Giroux 1985, xvi), to a discourse of hope. While research cannot ignore the significant resettlement and education challenges experienced by some young people of refugee background, there is an urgent need to focus on the successes of this particular group and to understand the conditions through which success is generated and made possible. Rather than focusing on what doesn't work and the challenges and difficulties of resettlement, a focus on what works, and how it works, might help to position this group as agentic, capable, resilient and resourceful. Therefore, we suggest the need for further research into the nature of the networks, and the relationships that facilitate the generation of social capital by 'successful' refugee young people and their families. We also suggest the need for school-based research that investigates how successful young people, as defined and understood in this article, negotiate discourses of schooling, and how they draw upon the resources and social capital generated in out-of-school activities and networks to achieve success in school.

\section{Acknowledgements}

We would like to acknowledge the participants who generously gave their time to this study, and the support of the other research team members; Dr. Jae Major and Dr. Kiprono Langat.

\section{Notes}

\footnotetext{
${ }^{\mathrm{i}}$ All names are pseudonyms

${ }^{i i}$ We adopt the definition of a refugee as 'someone who has been assessed by a national government or an international agency (such as the Office of the High Commissioner for Refugees (UNHCR)) and meets the criteria set out under the Convention relating to the Status of Refugees 1951 (Refugee Convention)' (Australian Human Rights Commission, 2008).

iii The Australian Bureau of Statistics (ABS) defines urban and rural localities on the basis of their population range. Regions are non-urban areas grouped on the basis of their remoteness from services (for further information see:
} 
http://www.abs.gov.au/websitedbs/D3310114.nsf/home/frequently+asked+questions\#Ancho

r7. see also: http://www.aifs.gov.au/institute/pubs/factssheets/2011/fs201103.pdf). In this paper we use the term 'rural' to describe all non-urban locations.

\section{References:}

Bačáková, M. 2011. "Developing Inclusive Educational Practices for Refugee Children in the Czech Republic." Intercultural Education 22 (2): 163-175. doi: 10.1080/14675986.2011.567073.

Bassani, C. (2008). Parent classroom involvement and the development of social capital: a reading program in East Vancouver. Journal of Educational Enquiry 8(2): 51-70.

Bohnert, A. M., Wargo Aikins, J., and Arola, N. T. 2013. "Regrouping: Organized Activity Involvement and Social Adjustment Across the Transition to High School." New Directions for Child and Adolescent Development 140: 57-75. doi: 10.1002/cad.20037.

Bourdieu, P. 1987. "What Makes a Social Class? On the Theoretical and Practical Existence of Groups". Berkeley Journal of Sociololgy 32: 1-17.

Brough, M., C. Bond J. Hunt, D. JenkinS, C. Shannon and Schubert, L. 2006. "Social Capital Meets Identity: Aboriginality in an Urban Setting." Journal of Sociology 42 (4): 396-411. doi: 10.1177/1440783306069996.

Clarke, A. 2005. Situational Analysis: Grounded Theory After the Postmodern Turn. Thousand Oaks, CA: Sage.

Coleman, J. (1988). Social capital in the creation of human capital. The American Journal of Sociology 94 (S): 94-120.

Community Relations Commission. 2006. Report of the Community Relations Commission for a multicultural NSW: Investigation into African Humanitarian Settlement in NSW. Sydney: Community Relations Commission.

Department of Immigration and Citizenship. ND. "Community Information Summary. Sudan-born." Accessed Jan. 2014. http://www.immi.gov.au/media/publications/statistics/comm-summ/source.htm

Eccles, J. S., Barber, B. L., Stone, M. And Hunt, J. 2003. "Extracurricular Activities and Adolescent Development.” Journal of Social Issues 59 (4): 865-889.

Edgeworth, K. 2012. "Discourses of Inclusion and Exclusion: Ethnic Minority, Muslim and Refugee Students in Rural Schools.” PhD diss., Charles Sturt University, Australia.

Giroux, H. A. 1985. "Introduction.” In Freire, P. The Politics of Education: Culture, Power and Liberation. Connecticut: Bergin and Garvey.

Hebbani, A. Obijiofor, L. and Bristed, H. 2009. "Generational Differences Faced by Sudanese Refugee Women Settling in Australia." Intercultural Communication Studies XVIII (1): 66-82.

Hutchison, K. 2012. "A Labour of Love: Mothers, Emotional Capital and Homework." Gender and Education 24 (2):195-212. doi: 10.1080/09540253.2011.602329.

Institute for Community Ethnicity and Policy Initiatives. 2005. Cultural Diversity and Economic Development in Four Regional Australian Communities. Melbourne, Victoria: Department of Transport and Regional Services. 
Lenette, C., Brough, M. and Cox, L. 2012. "Everyday Resilience: Narratives of Single Refugee Women with Children." Qualitative Social Work 12 (5): 637-653. doi:10.1177/1473325012449684.

Major, J.; Wilkinson, J.; Langat, K. and Santoro, N. 2013. Sudanese young people of refugee background in rural and regional Australia: social capital and education success. Australian and International Journal of Rural Education 23 (3): 95104.

Matthews, J. 2008. "Schooling and Settlement: Refugee Education in Australia." International Studies in Sociology of Education 18 (1): 31-45. doi: 10.1080/09620210802195947.

McBrien, J. L. 2005. "Educational Needs and Barriers for Refugee Students in the United States: A Review of the Literature." Review of Educational Research 75 (3): 329-364. URL:http://www.jstor.org/stable/3515985.

McGonigaL, J.; Doherty, R.; Allan, J.; Mills, S.; Catts, R.; Redford, M.; McDonald, A.; Mott, J.; and Buckley, C. 2007. "Social Capital, Social Inclusion and Changing School Contexts: A Scottish Perspective.” British Journal of Educational Studies 55 (1): 77-94. doi: 10.1111/j.1467-8527.2007.00362.x.

McPherson, M. 2010. ''I integrate, therefore I am': Contesting the Normalizing Discourse of Integrationism through Conversations with Refugee Women." Journal of Refugee Studies 23 (4): 546-570. doi: 10.1093/jrs/feq040.

Murray, K. E. 2010. "Sudanese Perspectives on Resettlement in Australia." Journal of Pacific Rim Psychology 4 (1): 30-43. URL http://dx.doi.org/10.1375/prp.4.1.30.

Nixon, C. 2011. "Working-Class Lesbian Parents' Emotional Engagement in their Children's Education: Intersections of Class and Sexuality." Sexualities 14 (1): 79-99. doi: 10.1177/1363460710390564.

Nowotny, H. 1981. "Women in Public Life in Austria.” In Access to power: Crossnational studies of women and elites, edited by C. F. Epstein and R. L. Coser London: George Allen \& Unwin.

Oliver, R., Haig, Y., and Grote, E. 2009. "Addressing the Educational Challenges Faced by African Refugee Background Students: Perceptions of West Australian Stakeholders." TESOL in Context 19 (1): 23-38.

Pugh, K., Every, D., and Hattam, R. 2012. "Inclusive Education for Students with Refugee Experience: Whole School Reform in a South Australian Primary School." The Australian Educational Researcher 39 (2):125-141. doi: 10.1007/s13384-011-0048-2.

Putnam, R. 2000. Bowling Alone: The Collapse and Revival of American Community. New York, NY: Simon and Schuster.

Ramsden, R. and Taket, A. 2013. "Social Capital and Somali Families in Australia." Journal of International Migration and Integration 14 (1): 99-117.

Reay, D. 2000. “A useful Extension of Bourdieu's Conceptual Framework? Emotional Capital as a Way of Understanding Mothers' Involvement in their Children's Education?" The Sociological Review 48 (4): 568-85. doi: 10.1111/1467954X.00233.

Santoro, N. 2013. "I really want to make a difference for these kids but it's just too hard": One Aboriginal teacher's experiences of moving away, moving on and moving up". International Journal of Qualitative Studies in Education 26 (8): 953-966. DOI: 10.1080/09518398.2012.724466 
Santoro, N. 2010. "'If it weren't for my mum...': The influence of Australian Indigenous mothers on their children's aspirations to teach". Gender and Education 22 (4): 419-429.

Strang, A. and Ager, A. 2010. "Refugee Integration: Emerging Trends and Remaining Agendas." Journal of Refugee Studies 23 (4): 589-605. URL: http://dx.doi.org/10.1093/jrs/feq046.

Strekalova, E. and Hoot, J. 2008. "What is Special About Special Needs of Refugee Children? Guidelines for Teachers." Multicultural Education 16 (1): 21-24. Taylor, S. 2008. "Schooling and the Settlement of Refugee Young People in Queensland: '...The challenges are massive'.” Social Alternatives 27 (3): 58-65.

Taylor, S., and Sidhu, R. K. 2012. "Supporting Refugee Students in Schools: What Constitutes Inclusive Education?" International Journal of Inclusive Education 16 (1): 39-56. doi: 10.1080/13603110903560085.

Terrion, J. 2006. "Building Social Capital in Vulnerable Families: Success Markers of a School-Based Intervention Program." Youth and Society 38(2): 155-176.

Tzanakis, M. (2013) "Social capital in Bourdieu's, Coleman's and Putnam's theory: empirical evidence and emergent measurement issues". Educate 13 (2): 2-23.

Wilkinson, J. and Langat, K. (2012). "Exploring educators' practices for African students from refugee backgrounds in an Australian regional high school". The Australasian Review of African Studies, 33(2): 158-177.

Windle, J. and Miller, J.2013. "Marginal Integration. The Reception of RefugeeBackground Students in Australian Schools." In Refugees, Immigrants and Education in the Global South, edited by L. Barnett and A. Ghaffar Kucher, 198-210. Milton Park: Routledge.

Woods, A. 2009. "Learning to Be Literate: Issues of Pedagogy for Recently Arrived Refugee Youth in Australia." Critical Inquiry in Language Studies 6 (1-2): 81101. doi: 10.1080/15427580802679468. 